\title{
The innovation research of Computer interactive technology applied in English teaching
}

\author{
Zhenzhen Xue
}

Zhengzhou university of industrial technology. Henan. China

Keywords: Computer interactive technology; English teaching

\begin{abstract}
Computer interactive technology is a product of the era development and the problems in the process of its advancement which exist in the understanding and the resource reserve are inevitable. For these phenomena, not only the auxiliary and order principle are supposed to be established in the process of applying the computer technology in English teaching, but also the CIT's application value ought to be reexamined. The specific training to teachers of different subjects needs to be strengthened and the construction of CIT network database should be consummated in time.
\end{abstract}

\section{Introduction}

Computer Interactive technology (CIT) is an assistant English teaching method, which has been widely used in various English teaching activities with the rapid development of computer and network technology since the early 1990s. By means of using a variety of software processing tools, such as PPT, FLASH, 3DMAX, PREMIERE, the English teaching contents are optimized in sound, image, graphics, video and other information processing, then the courseware's characteristics of richness, novelty, interestingness, figurativeness and organization are eventually obtained.[1] Information technology effectively support English teaching requires three conditions: material conditions, information literacy and application concept.[2] But in actual English teaching, the computer technology is applied in the rote learning framework, lack of originality and creativity. [3] PPT is only a substitute for the artificial board in the past and the computer is just used to play the PPT. This simplistic use of computer functions severely restricts the innovation and development of information technology. So how to make full use of computer technology, enrich the English teaching content and improve English teaching effect are need to discuss.

\section{The problems existing in the application of current computer technology in English teaching}

Teachers' understandings of CIT are polarized. The first kind of teachers relies too much on the CIT English teaching software, leading into electronic information infusion. To prepare a public class or classes for the match, sometimes it takes a person's or a team's too much energy in the courseware manufacture. They always pursuit pure and new in the editing platform, material making software and integration tools, and pursuit full and beauty in the courseware design. They make full use of the existing development tools, including those nonlinear editing and synthesis software, such as Premiere, VideoStudio, Combustion, those animation software, such as Flash, 3D Studio, Cool 3D，5D, those graphics editing software, such as Photoshop, Adobe ImageReady, and those general software, such as Author-ware, Powerpoint, JAVA, VB, Microsoft FrontPage, Macrome-dia Dreamweaver[4].Those software make teachers become slave of computer technology and loose the leading role in the class. The second kind of teachers just take the CIT as a replacement of traditional teacher's writing and move the course content mechanically to the screen. Although this approach can save time, it can't realize the promoting effect function of multimedia in the English teaching, at the same time it can cause textbook strangeness to students, turning into restarting reading textbooks. Both extreme phenomena have violated the basic law of education. In the pursuit of English teaching thought on "advanced" and "conservative" to keep the dynamic and static attitudes, there should be a kind of cracking method to remove two phenomena. 
Lack of the CIT resources. The lack is mainly showed as follows. Firstly, the developed CIT software are not good enough. From a professional point of view, the CIT software are developed by professionals, who don't have enough related subject knowledge, so the script cannot meet the scientificity and pertinence, resulting in some disciplines teachers incorrectly using CIT software in more professional. At the same time, due to the influence on software development and market needs, some have no suitable specialized disciplines software and only make use of other disciplines software, making it hard for teachers to hand. Secondly, the number of high-quality CIT courseware is too small. Due to the short application time of computer and network technology, the CIT software are not widely used and the development pace of CIT software is slow. Especially the lack of the talent team who keep good balance between technology and related subject knowledge causes the few number of high-quality CIT courseware.

The CIT software type is not corresponding with English teaching mode. The existing CIT English teaching pattern mainly has the following kinds. One is simulation experiment CIT and this kind of software is mainly applied in the physical and chemical reaction experiment. Two is demonstrating CIT and this kind of software is mainly applied in abstract mathematics and physical phenomena and processes. Three is self-test practice type CIT and this kind of software is mainly applied in autonomy learning or stage inspection[5]. Four is instructed type CIT and this kind of software is mainly applied in lectures or autonomy learning. The modular and systematic design at the beginning development of the CIT software cannot make some teachers' ideas into reality. At the meanwhile, due to the factors related to intellectual property rights, those courseware which have been formed are only allowed to be played mechanically on the computer and cannot be flexible used for teachers, resulting in being abandoned for no selective choice.

\section{The principle established in the process of applying computer technology in English teaching}

CIT has great practical significance to modern education and incomparable advantage over other English teaching means. Therefore, we should positively develop and utilize the function of CIT on the basis of no conflict to basic education law and compliance to the principle of education.

CIT can't replace teachers' dominant position. In comparison of computer aided English teaching and the traditional education English teaching means, the advantage of the computer aided English teaching is obvious, but teachers' dominant position in the process of English teaching cannot be ignored. Primary and secondary should be clear, and position accurate. In the process of practical English teaching prominent teachers' vivid lectures, brief blackboard writing and timely feedback communication between teachers and students are very necessary, and the effect of mobilizing students actively into English teaching process cannot be replaced by other English teaching means. If teachers' dominant position does not exist in the practical English teaching, the practical English teaching effect will be greatly reduced. A class popular with students holds the key in teacher's lecture and the multimedia only has the auxiliary function. Therefore, the English teaching mode of teacher-dominating and students-oriented should be defined in the practical English teaching process.

Correct choice to arrange courseware content. The nature of the multimedia English teaching lies in the teacher presenting the content clearly and systematically, but not making the students achieve the purpose of self learning through multimedia. Therefore, In the process of making and use of multimedia English teaching courseware teachers cannot blindly abuse of courseware for English teaching or weave all the English teaching content and blackboard writing into courseware played in class without trade-offs. And moreover, teachers should attach great importance to the content and should not put all the irrelevant colorful things in front of students, achieving the goal of an eye-catching. These courseware often do not separately emphasis on the important and difficult points, and even inordinate, and eventually backfire. Hence, in the courseware manufacture process, we should pay attention to the applicability and practicability, and the courseware should be based on the English teaching outline and English teaching goals. It also should be adapt to students' age and cognitive law, and highlights the English teaching emphasis and difficulties. If teachers have the targeted English teaching goal and make the courseware according to the students, 
which are full of content and visual impact, it will finally achieve the expected English teaching effect.

Persistently stick to the students' need. During the process of using computer technology making multimedia courseware, students ought to be the demand body. Teachers should stand in the perspective of students considering accuracy of topic selection, acceptation and cognition, interactivity, aesthetic standard, the cultivation of critical thinking factors whether are suitable. Under this premise, the teachers can design and make the courseware which has a strong pertinence to students.

\section{Improve all aspects of computer aided English teaching}

In order to be able to put the CIT's real application in the English teaching process, the work of various parts ought to be done well.

Reviewing the CIT's application value. In the CIT's daily English teaching process, teachers consciously or unconsciously use them for the English teaching. However both education management institutions and schools should be cautious to the problem that different disciplines teachers use the CIT. Neither unified treatment, nor let it be. Those departments should make targeted reasonable request to different disciplines. For example, during the higher mathematics class, if teacher use too much multimedia, students could not keep pace with the teacher due to the fast demonstrating and no reasoning process in which teacher leads students. Thus, teacher should take more use of traditional plate to guide students to gradually transform of thinking. But for the computer, mechanics, architecture class, the visualization and dynamic graphics can be used to simulate. So much more research input could be increased to make more auxiliary courseware. Each course should be relocated in English teaching practice constantly, cognized and modified to find really suitable CIT software and courseware for their disciplines.

Targeted training of utilizing the CIT software for different disciplines teachers. To promote the rapid development of computer assisted instruction, such things should be finished. Firstly, leaders should gain the certain knowledge of CIT and also pay attention to its promotion. Under the existing system in China, any work style which has common sense needs to be promoted by higher institutions and leaders on the premise of main demand. Of course, leaders also get familiar with the CIT in the process of studying, communication and training. After direct acknowledges and grasp of the rule and method of the matter's development, it is much easier for the leaders to promote the rapid development of the transaction. Secondly, the ability training of teachers using the multimedia auxiliary English teaching should be emphasized. According to the disciplines characteristics, teachers' training ought to be targeted and focused on short-term hierarchically to improve their information literacy and the ability of computer application.

Strengthening the construction of the CIT resource. Each education unit ought to have its own CIT resource for self-use or partly network share. The main ways of the construction of CIT resource are as follows. Firstly, purchase and collect related data in the early stage, such as video, audio, images and animation. Secondly, form CIT manufacture teams and vigorously develop courseware suitable for their discipline characteristic. According to the needs of those subjects, form big team to develop the discipline CIT resource, then it is divided into several groups by the chapter of each subject. Both teachers and professional participate in and cooperate to make courseware of the subject, and finally integrated system is jointly used to feedback and modification. Through repeated daily English teaching practice and adjustment, it can ensure the timeliness and accuracy of the courseware, increasing energy and use value of the CIT resource. Thirdly, collect the corresponding software support system, such as slides making software PowerPoint, diagramming making software Visio and AutoCAD, image processing software Photoshop, development integration platform Authorware and Geometer sketchpad, animation making software Flash, 3DMAX, Maya, video editing software Corel VideoStudio, EDIUS, Adobe Premier, Adobe After Effects.

Computer assisted instruction technology come into being with the needs of the time education and staggered in the time development, and will act as appropriate auxiliary role in the future 
English teaching practice. It obtains more needs of the management' persistent promotion, teachers' continuous efforts and the subject students' actively participation to accurately locate the function and mode of the computer aided English teaching.

\section{Reference}

[1] Lin Zhu, Wei Qi. The Design and Practice of the Computer Aided Design. China University English teaching. 2012.(7).55-60.

[2] Yunwen Li, Yuan Lv, Lishang Zhu. The Evolution of the Teachers' Concept to Information Technology Application. Curriculum, English teaching Materials and Instruction Methods. 2011, (10). 91-100.

[3] Guiping Chen. The Problems and Countermeasures in the Computer Aided English teaching. Education and Vocation. 2014, (6).163-170.

[4]Munro, D. A. Sustainability: Rhetoric or Reality? In Trzyna, \& Thaddeus (Eds.). California: Center for the Envi-ronment and Public Policy.2005.

[5]Newman, P. Sustainability and Cities. Washington: Island Press.1998. 